\title{
Lajos Hopp, Un épistolier et traducteur littéraire à l' orée des Lumières: Kelemen Mikes, Recueil d'essais
}

\section{Katelin Bódi}

\section{(2) OpenEdition}

1 Journals

\section{Édition électronique}

URL : http://journals.openedition.org/studifrancesi/5331

DOI : 10.4000/studifrancesi.5331

ISSN : 2421-5856

Éditeur

Rosenberg \& Sellier

\section{Édition imprimée}

Date de publication : 1 décembre 2016

Pagination : 528

ISSN : 0039-2944

\section{Référence électronique}

Katelin Bódi, «Lajos Hopp, Un épistolier et traducteur littéraire à l'orée des Lumières: Kelemen Mikes,

Recueil d'essais », Studi Francesi [En ligne], 180 (LX | III) | 2016, mis en ligne le 01 janvier 2017, consulté le 18 septembre 2020. URL : http://journals.openedition.org/studifrancesi/5331 ; DOI : https://doi.org/ 10.4000/studifrancesi.5331

Ce document a été généré automatiquement le 18 septembre 2020.

\section{(c)}

Studi Francesi è distribuita con Licenza Creative Commons Attribuzione - Non commerciale - Non opere derivate 4.0 Internazionale. 


\title{
Lajos Hopp, Un épistolier et traducteur littéraire à l'orée des Lumières: Kelemen Mikes, Recueil d'essais
}

\author{
Katelin Bódi
}

\section{RÉFÉRENCE}

LAJOS HOPP, Un épistolier et traducteur littéraire à l'orée des Lumières: Kelemen Mikes, Recueil d'essais, sous la direction de Gábor Tüskés, publié par Imre Vörös et Anna Tüskés, Szeged, JATEPress, coll. «Felvilágosodás - Lumières - Enlightenment - Aufklärung» 3, 2014, $174 \mathrm{pp}$.

1 Devenir l'héritier d'un œuvre scientifique ne comporte pas seulement la tâche de conserver, mais également la responsabilité d'utiliser les résultats de cet héritage. Celui de Lajos Hopp (1927-1996), spécialiste des recherches dix-huitièmistes, mérite bien cette fructification par la postérité, avant tout par son affinité aux relations interculturelles de la littérature hongroise des Lumières. Ses recherches concernant François II Rákóczi, prince de Transylvanie et Kelemen Mikes, membre de sa cour condamnés à l'exil en Turquie après la défaite de la guerre d'indépendance contre les Habsbourgs - montrent l'influence de la culture, de la littérature et du style galants et moralisants de la France de la fin du XVII et du début du XVIII ${ }^{\mathrm{e}}$ siècle. Lajos Hopp, membre de l'Institut Littéraire de l'Académie des Sciences de Hongrie a publié entre 1966 et 1988 l'édition critique en six volumes des œuvres complètes de Kelemen Mikes qu'il a parachevée par des monographies et par des études. Le troisième volume de la collection Felvilágosodás - Lumières - Enlightenment - Aufklärung, éditée par le Centre de recherches «Lumières Franco-Hongroises» de l'Université de Szeged a rassemblé douze études de Lajos Hopp sur le sujet du genre épistolaire du xvIII ${ }^{\mathrm{e}}$ siècle, écrites premièrement en hongrois, publiées partiellement en français. Ces dernières sont entrées dans le discours des recherches littéraires en France à partir des années 1960, 
grâce aux contacts scientifiques avec des historiens du genre épistolaire comme Bernard Bray par exemple, mais une édition attentive de ces études était nécessaire pour les recherches qui seront menées à l'avenir. Une partie des textes récemment édités est focalisée sur le genre épistolaire et en particulier sur les Lettres de Turquie de Mikes, écrites en exil entre 1717 et 1758, inspirées par le goût français de l'époque de transposer les expériences personnelles dans une forme littéraire. La première édition des Lettres paraît en 1794, au moment où les correspondances littéraires et le roman épistolaire atteignent leur apogée en Hongrie, ce qui rehausse encore plus la valeur des résultats scientifiques de Lajos Hopp. Une autre partie des études traite du problème de la traduction, de l'adaptation et de l'imitation, question cardinale de l'époque qui permet de relever l'influence des différentes traditions culturelles européennes et d'étudier les styles et les thèmes typiques: l'adaptation des Journées amusantes de Mikes en est un bel exemple. Certaines études du recueil traitent également de l'héritage de Mikes à la fin du XVIII ${ }^{\mathrm{e}}$ siècle et du transfert littéraire et culturel de l'exil.

Cs études peuvent compléter le travail que Lajos Hopp a entamé sur l'œuvre de Kelemen Mikes, à l'occasion du $250^{\mathrm{e}}$ anniversaire de la mort de l'écrivain: l'édition de ses Lettres de Turquie en français (voir: «Studi Francesi» n. 167, 2012, pp. 322-323) et la publication des communications du colloque organisé à Budapest, les 12-15 octobre 2011. Néanmoins une édition en ligne du recueil pourrait donner davantage de visibilité à ce geste d'hommage. 